\title{
Transience and Persistence of Natural Hydrocarbon Seepage in Mississippi
}

\section{Canyon, Gulf of Mexico}

Oscar Garcia (oscar.garcia@watermapping.com) ${ }^{1}$, lan MacDonald (imacdonald@fsu.edu) 1, Mauricio Silva (mauricio.silva.a@gmail.com) ${ }^{1}$,William Shedd (william.shedd@boem.gov) ${ }^{2}$, Samira Daneghar Asl (samira.daneshgar@gmail.com) ${ }^{1}$, Bonny Schumaker (bonny@onwingsofcare.org) ${ }^{3}$

${ }^{1}$ WaterMapping LLC, Director, Tallahassee FL 32312.

${ }^{2}$ Florida State University, EOAS Dept, Tallahassee FL 32306.

${ }^{3}$ Bureau of Ocean Energy Management, New Orleans LA

${ }^{4}$ On Wings of Care, La Canada CA 91012-0583

* Corresponding author 


\section{Abstract}

Analysis of the magnitude of oil discharged from natural hydrocarbon seeps can improve understanding of the carbon cycle and the Gulf of Mexico (GOM) ecosystem. With use of a large archive of remote sensing data, in combination with geophysical and multibeam data, we identified, mapped, and characterized natural hydrocarbon seeps in the Macondo prospect region near the wreck site of the drill-rig Deepwater Horizon (DWH). Satellite image processing and the cluster analysis revealed locations of previously undetected seep zones. Including duplicate detections, a total of 562 individual gas plumes were also observed in multibeam surveys. In total, SAR imagery confirmed 52 oil-producing SZ in the study area. In almost all cases gas plumes were associated with oil-producing seep zones. The cluster of seeps in the vicinity of lease block MC302 appeared to host the most persistent and prolific oil vents. Oil slicks and gas plumes observed over the DWH site were consistent with discharges of residual oil from the wreckage. In contrast with highly persistent oil seeps observed in the Green Canyon and Garden Banks lease areas, the seeps in the vicinity of Macondo Prospect were intermittent. The difference in the number of seeps and the quantity of surface oil detected in Green Canyon was almost two orders of magnitude greater than in Mississippi Canyon. 


\section{Introduction}

Seafloor hydrocarbon fluid and gas seepage is a prevalent process on the continental margin of the Gulf of Mexico (GOM). In this paper, we use Synthetic Aperture Radar (SAR) satellite imagery, multibeam swath-mapper data, 3D seismic data, aerial photography, and direct observations from ROVs and submarine ALVIN to analyze seepage activity in the region of the Macondo Prospect in the Mississippi Canyon lease area (abbreviated MC). This area (shown in Figure 1A) has been intensively monitored during and after the Deepwater Horizon (DWH) blowout. The great magnitude of hydrocarbon discharges from DWH and the unprecedented complexity of the disaster have created a scenario in which post-response detection of oil and gas near the $\mathrm{MC}$ challenges any simple interpretations. The situation is further complicated by existence of nearby natural hydrocarbon seeps and recent initiation of exploration drilling activity adjacent to the accident scene by a new commercial concern. Access to data archived prior to and after the DWH incident allows us to evaluate the seepage activity on the region. The main objective of this paper is to identify the areas where oil seepage is present in the general region of the DWH accident site, and characterize the magnitude and temporal variability of the oil seeps. To illustrate our data, analysis, and results, Figures $1 A, 1 B, 2,3 A, 4 A$, and 8 are maps that cover the exact same area but show different features associated with the seepage. These maps are constructed using WGS-1984 projection and their datasets are available for downloading at www.sarsea.org/MC252study 


\subsection{Natural Seepage Processes}

Due to their lower specific gravity and to local formation over-pressure, hydrocarbons will tend to migrate vertically through higher permeability zones in the subsurface, moving along fault planes, sedimentary bedding planes, or through permeable stratigraphic units to create Seep Zones (SZ) on the seafloor (Cook and D'Onfro, 1991; Garcia-Pineda et al., 2010; Reilly et al., 1996; Roberts and Carney, 1997). These SZ are sometimes accompanied by mud volcanism and discharge of brines and cognate fluids , (Judd and Hovland, 2007; Whelan et al., 2005). The SZ and their associated features are of interest because they occur in areas that may contain substantial accumulations of gas hydrate, a methane ice-like substance that is both a trophic source for chemosynthetic communities and a potential economic energy source (Kvenvolden and Cooper, 2003; Roberts et al., 1999; Sassen et al., 2001). Formation of gas hydrate reduces sediment porosity and flux (Roberts et al., 1999). However, where flow exceeds equilibrium consumption and hydrate formation rates, a fraction of gas and oil escapes into the water column from discrete seep vents within a SZ (Garcia-Pineda et al., 2010).

As described in Garcia-Pineda et al. (2010) and elsewhere (Römer et al., 2012), one SZ can host multiple discrete seep vents. Gas and oil is released through vents into the water column as small $(1-10 \mathrm{~mm}$ ) bubbles (MacDonald et al., 2002). Oil often coats the walls of the bubbles and rise speed is controlled by the combined buoyancy of the oil and gas in the bubble. During its vertical transit through the water column, plumes of oil bubbles may be laterally deflected by currents (Leifer and MacDonald, 2003). However, the cross-section of bubble plumes does not expand substantially between the sea floor and the sea surface. During its 
path through the water column a significant part of gas at natural seeps dissolves into the water (Leifer and MacDonald, 2003). Once oil reaches the sea surface it forms a thin layer, commonly called an oil slick, that drifts along a curvilinear path determined by wind and surface currents; the persistence of oil slicks is strongly influenced by wind strength and sea state (De Beukelaer et al., 2003).

Evaluation and identification of SZ typically occurs through satellite remote sensing and geophysical means (e.g. seismic, side-scan sonar) as geophysical data are able to show us detailed information about the structure and geology of a seep (Garcia-Pineda et al., 2014). There is good evidence that natural seeps are episodic in geologic time (Roberts and Carney, 1997). Furthermore, hydrocarbon discharges associated with eruptive mud volcanism can be episodically large (MacDonald et al., 2000; MacDonald and Peccini, 2009). However, seeps detected by SAR in the central and western Gulf of Mexico have generally been persistent on annual and decadal scales (De Beukelaer et al., 2003; Garcia-Pineda et al., 2010; Garcia-Pineda Oscar, 2009). Active oil seeps that can be detected with SAR represent a subset of the total array of geophysical features generated by hydrocarbon migration on the continental slope. Additional work is needed to determine the relationship between oil seeps visible on the sea surface, the geology of the underlying formations, and the biological response of the deep-sea benthos to hydrocarbon enrichment. The hypothesis that natural seeps producing surface oil slicks are perennial features will be tested in this paper by examining processes in a less-studied northeastern region of the Gulf of Mexico with a large sample of satellite remote sensing images. 


\section{Materials and Methods.}

Since the launch of Seasat, the first civilian synthetic aperture radar (SAR) satellite, on June 26,1978 , thousands of SAR images have been collected over the GOM. Through data sharing agreements with NASA, NOAA, and ESA, we reviewed 740 SAR images that imaged all or part of the area of interest. A total of 343 SAR images were collected over the Macondo vicinity prior to DWH. During the spill, between April and August 2010, 269 images were acquired over the same region. Similarly, 128 SAR images were collected after DWH and added into the analysis. Our dataset consist of images collected by SeaSat, JERS-1, ERS1, ENVISAT, SPOT, TerraSAR-X, Radarsat 1-2, CosmoSky-Med 1-4, and ALOS. A temporal coverage of our dataset is shown in Table 1.

\subsection{SAR data processing}

SAR images were processed and analyzed following the procedures described by GarciaPineda et al. (2009, and 2010), briefly summarized here: Preliminary inspection of the image determines the overall ocean features. The texture of the image is then evaluated to determine the wind conditions. When regions of very low wind speeds are present, ripple-free water and biogenic films create irregular, radar-dark regions that are difficult to distinguish from actual oil slicks. These features are masked to exclude them from further analysis. Two GIS layers are created for each image: The first layer is a polygon shapefile outlining the area of the SAR image footprint. This footprint layer receives the output of texture classifying neural network algorithm (TCNNA) procedure described by Garcia-Pineda et al. (2010), which includes the area of all SAR image pixels identified by the semi-supervised algorithm, not including any 
exclusionary masks. The second layer is a point shapefile that will contain oil slick origin (OSO) points, which are single points within detected oil slicks (see Garcia-Pineda et al. 2010). OSO points are identified by the shape of floating oil layers because origins tend to be the wider and more distinct ends of curvilinear oil slick features, which narrow and attenuate with increasing distance from the point where fresh oil reaches the sea surface. After determining the OSO points in the image, the depth data is then merged with each OSO attribute. This merged information will help fulfill further steps and will more effectively determine the bubble stream deflection through the water column.

\subsection{Multibeam data collection}

Rising gas bubbles in water are very efficient at scattering acoustic energy, resulting in a flare-shaped reflection (De Beukelaer et al., 2003; Nikolovska et al., 2008). Scattering intensity is controlled by variables such as gas type, bubble diameter, rising speed, surface tension of gas bubble, water depth, and temperature (Nikolovska et al., 2008). Bubbles in the size range commonly observed at natural seeps $(0.1-1 \mathrm{~cm})$ are acoustically resonant at depths greater than $100 \mathrm{~m}$ and can be detected with a wide range of acoustic sensors operating at frequencies 2 to 384 kHz (De Beukelaer et al., 2003).

Multibeam data was collected during the Ecosystem Effects of Oil and Gas in the Gulf (ECOGIG) cruise: "Long-term effects of the DWH discharge" on board the Schmidt Ocean Institute R/V Falkor, in November 2012. The expedition was focused on acquiring highresolution $\mathrm{MB}$ data over the MC-252 lease block and the surrounding area, using a Kongsberg Simrad EM 302 multi-beam echo sounder (30 to $34 \mathrm{KHz}$ ). Surveys were conducted 8-10 
October, 2012 covering portions of 20 lease blocks (approx. $500 \mathrm{~km}^{2}$ ). Hydroacoustic anomalies on the water column generated by gas and oil plumes were extracted and exported into 3D volume figures using FMMidWater Toolbolx and plotted on Fledermaus with the multibeam map in order to localize their seabed source. Additional multibeam swathmapper data were evaluated from the 2011 expedition of R/V Okeanos. Multibeam surveys (Okeanos and Falkor) were not identical, but the two surveys together covered the entire area of interest shown in Figure 1.

\subsection{Geophysical Data}

Using data collected for energy exploration, geoscientists at the Bureau of Ocean Energy Management (BOEM) have identified and mapped over 21,000 water bottom (seafloor) seismic amplitude anomalies in the deep water northern Gulf of Mexico based on 3-D timemigrated seismic surveys (Frye, 2008). These are areas of anomalously high or low reflectivity

response compared to background response. Results cover over $400,000 \mathrm{~km}^{2}$ (156,000 sq mi) of seismic data interpretation, with most areas having overlapping seismic coverage by two or more surveys. The water bottom horizon was completely mapped over these surveys using hand-interpreted seed lines and automated picking routines to interpolate between lines. The seismic amplitude was then displayed in map view. Areas with anomalously high positive and low positive or negative amplitudes were identified and outlined. The amplitude maps were cross checked with the vertical seismic profiles to verify correctness in the automated interpretation. Blanking and/or visible migration pathways (e.g. faults, gas chimneys) are often visible in the subsurface up to the water bottom in vertical seismic profiles beneath most of the 
amplitude anomalies Gulf-wide. BOEM, NOAA, and industry contractors have confirmed over 100 of the anomalies as hydrocarbon seeps and carbonate hard grounds through surveys with submersible, ROV, AUV, multibeam water column mapping, camera sled, and collection by piston core and trawling.

Areas which show a high positive amplitude response relative to the normal background response have been outlined as positive anomalies (Frye, 2008). Most of these positive anomalies have been found to exhibit a slow to moderate rate of hydrocarbon seepage. The positive amplitude response on the seismic data has been found to be caused by the presence of carbonate hard grounds created by microbial consumption of hydrocarbon in the sediments at these seeps, producing calcium carbonate in the process.

The subsurface structures in the study area were profiled in a continuous seismic section along a track chosen to pass through areas of active seepage and through the failed Macondo exploration well in MC252 where the DWH wreckage is located.

\subsection{Aerial observations}

Direct observation of oil slicks from small aircraft flying at low altitudes provided details that could not be resolved from satellite remote sensing and could not be observed from surface vessels. Airborne observers have been able to direct scientists in small boats to oil drops as they broke the ocean surface, and before they dispersed into thin layers, so that samples of the floating oil could be collected for chemical analysis (Aeppli et al., 2013). Details of the surface oil slicks near MC252 were photographed using a digital camera fitted with a 14 
$\mathrm{mm}$ lens and vertically mounted in the lower fuselage of a small airplane. Images were recorded at $4 \mathrm{~s}$ intervals while the airplane was piloted over the line of floating oil at an altitude of $120 \mathrm{~m}$. Navigation fixes (location and altitude) were recorded at $1 \mathrm{~s}$ intervals using the airplane's GPS receiver. Individual images were scaled using the acceptance angle of the lens $\left(102^{\circ}\right)$ calibrated by imaging objects of known size (ships) and groups of images were rescaled to a constant resolution of $18 \mathrm{~cm}$ per pixel. Multiple images were merged into a mosaic using Photoshop Creative Suite ${ }^{\odot}$ software; the completed mosaic was geo-referenced based on aircraft navigation fixes. Using the supervised classification tool in Geomatica 2014 software, the pixels in the mosaic of the aerial photographs were classified into two thickness classes using NOAA classification criteria: silvery sheen $(0.05-0.4 \mu \mathrm{m})$ and rainbow sheen $(0.5-5 \mu \mathrm{m})$ (NOAA Hazmat, 2012); the number of pixels in each class was counted.

\subsection{Seafloor observation}

The debris field around the DWH was directly observed during a $~ 6 \mathrm{~h}$ dive with an ROV submersible deployed from R/V Falkor (8 November 2012). The ROV descended to the seafloor at $1500 \mathrm{~m}$ and explored the debris that had been imaged by multibeam using video and forward looking sonar. Entanglement hazards encountered among the debris forced curtailment of this effort. In a separate effort, the seeps at Gloria dome were visited with submarine ALVIN during dive number 4688 (31 March 2014). The submersible descended to the seafloor at a depth of about $1500 \mathrm{~m}$ and conducted a systematic search in the vicinity of gas flares identified in the multibeam survey conducted by R/V Falkor. Photo-documentation was 
conducted with a digital single-lens reflex camera (also called DSLR) deployed in a deep-sea housing with high-intensity LED lamps.

\section{RESULTS}

Figure $1 \mathrm{~B}$ shows the location of all the OSO points detected among the 740 candidate SAR images; oil slicks appeared in 219 of these images. However, in a number of cases when weather and sensor conditions were suitable for seepage detection, oil slicks were not detected. Satellite image processing and the cluster analysis (Garcia-Pineda et al., 2010) revealed locations of previously undetected seeps. Combining these results with the gas plumes detected in multibeam, we found gas plumes associated with most but not all, SZ. There were numerous examples of SZ with gas plumes but no detection of surface oil slicks. In total, SAR imagery confirmed 52 active oil-producing SZ on the study area (Fig. 2). Compared with an earlier remote sensing inventory of SZ in this region (MacDonald, 2011), the present study found an additional 13 previously undocumented oil-producing SZ. Gas plumes were detected in surveys conducted by R/V Okeanus and/or RV Falkor at 40 of the oil producing SZ. Gas plumes were detected near the DWH site; however, as discussed below, detection of floating oil was restricted. The multibeam data, geophysical anomalies, and the aerial and seafloor observations confirmed the relationship between surface oil slicks, bubble plumes in the water column, seafloor geology (e.g. carbonates), and geophysical features. The following section describes the corroborating evidence regarding the characteristic of oil and gas seeps in the Macondo Prospect. 


\subsection{Water column gas plumes, geophysical structures, and aerial and submersible observations}

Multibeam and Acoustic backscatter anomalies surveys (R/V Okeanos and R/V Falkor) were not identical in coverage but they used the same instrument (Kongsberg EM302). Both surveys together covered the entire study area with repeated coverage over Biloxi, Gloria, and Mitchell Domes as well as the DWH wreck site. In general, gas plumes were most often detected on the up-slope margins of salt domes (Fig. 3A) were backscatter anomalies were also detected.

The densest clusters of water column targets were observed over Dauphin, Gloria, and Biloxi Domes (Fig. 3A). These plumes extended hundreds of meters above the seafloor, but in no cases did they reach the surface. Seep zones with stronger reflectivity evidently had plumes that extended farther above the seafloor, as can be seen by comparing plumes at Biloxi and Gloria Domes (Fig. 3B). Gas plumes that were not associated with salt structures were observed at several locations, most notably in association with the debris field surrounding the Macondo Well (Fig. 3A). The wreck of the Deepwater Horizon was clearly resolved as a large rectangular object in the survey conducted on R/V Falkor (Fig. 3B). In those regions where the multibeam data from both surveys overlaps, we can observe a general coincidence of plumes observed, however in several cases the number and location of plumes vary slightly suggesting lateral displacement of the plume vent on the seafloor as pointed out in previous investigations (Garcia-Pineda et al., 2014). 
Surface reflectance anomalies identified in the geophysical data associated with most of the gas plume sources and were principally interpreted as carbonates or similar hard-ground features, with low-reflectance anomalies interpreted as higher flux seep areas (Fig 4A). Previous investigations (MacDonald et al., 2003; Roberts et al., 2010), have found chemosynthetic communities associated with the carbonate hard-grounds. The geophysical profile, which was output for a line passing through Biloxi Dome, DWH site, Gloria and Dauphine Domes, confirmed clear migration channels in association with the active gas seeps on the flanks of the domes, but not in the vicinity of the DWH wreck site or the Macondo Well (Fig. 4B). Thus, the geophysical data indicate a deep subbottom source for the gas plumes and oil slicks near the salt domes, but show no evidence that the gas that generated the plumes near the wreckage migrated from a deep subbottom source.

Although the ROV exploration of the DWH debris field was curtailed before the entire area had been surveyed, no visual or sonar evidence of ongoing seepage was detected. Observers in submarine ALVIN surveyed the northwest portion of Gloria Dome to verify the gas plumes observed in the R/V Falkor multibeam survey (Fig. 5). The submersible covered transects totaling $2.3 \mathrm{~km}$ during a $2.25 \mathrm{~h}$ survey. Two active seep areas were identified located near $28^{\circ} 43.32^{\prime} \mathrm{N}, 88^{\circ} 19.60^{\prime} \mathrm{W}$ at a depth of $1467 \mathrm{~m}$ (Fig. 5). Each seep comprised a small ( $<5$ $\mathrm{m}^{2}$ ) patch of light colored sediment coated with white microbial communities mat and sulfur deposits. Dead bivalve shells, carbonate rubble, and sparse tubeworm provided evidence for a history of hydrocarbon discharge. However, active hydrocarbon seepage was very limited on this occasion. Observers noted small drops of oil poised at the interface and occasionally rising into the water. Compression of the sediments when the submarine landed for sampling 
operations caused additional releases of oil and gas bubbles. Disturbance of the sediments during sampling caused further releases. A hard substrate less than $5 \mathrm{~cm}$ under the mat and rubble suggested a subsurface layer of gas hydrate may have been present. Sediment cores from the edge of the seep degassed violently when the submarine ascended.

\subsection{Aerial observations}

The MC253 and MC253 area was surveyed using aerial photography on 5 October 2012. However the most prominent oil slick was observed several kilometers to the northeast of the DWH and did not originate in the wreckage field of the DWH(Fig. 6B). In all, the oil slick comprised $156324 \mathrm{~m}^{2}$ silver sheen and $56173 \mathrm{~m}^{2}$ rainbow sheen (NOAA Hazmat, 2012). This observation was necessary to confirm that features observed from SAR were oil slicks and not other look-alikes (e.g. sargasum). Considering the thickness of $0.1 \mu \mathrm{m}$ and $1 \mu \mathrm{m}$, respectively, for oil in the silver and rainbow sheen areas as reasonable scalars for the two thickness classes, the volume of the discharged silver and rainbow sheen oil is $0.015 \mathrm{~m}^{3}$ and $0.056 \mathrm{~m}^{3}$. The aerial observations were repeated on 9 November 2012, when samples of the floating oil were collected directly over the DWH wreck location. On this occasion, the larger oil slick to the northeast was not observed and seepage in a $5 \mathrm{~km}$ radius around the DWH site was restricted to the smaller droplets collected by the small boat. Analysis of the floating oil found alkane signatures consistent with artificial drilling fluids, suggesting that this oil originated from the DWH wreckage (R. Nelson, personal communication; (Aeppli et al., 2013). The source of oil in the larger oil slick could not be positively identified. 


\subsection{Temporal variability of oil seepage.}

In contrast with highly persistent oil seeps observed in the Green Canyon and Garden Banks lease areas (De Beukelaer, MacDonald et al. 2003, Garcia, MacDonald et al. 2010) the seeps in the vicinity of Macondo Prospect were intermittent. Using derived wind history from the NCEP Climate Forecast System Reanalysis (CFSR), we selected a subset 42 SAR images that had ideal weather conditions for oil seepage detection (with winds between 3-7 ms ${ }^{-1}$ ). We found a high degree of variability in the activity of oil seeps in the area. On frequent occasions when optimal weather conditions for oil detection occurred, many of the seeps remained undetected. The most active cluster of seeps (located in MC302) was detected in $53 \%$ of the images when optimal weather conditions occurred. In contrast, there are several SZ where seep oil was rarely detected (oil detected in 3-5 of the 42 images selected). Figure 2 shows the relative frequency of oil slick observation for the lease blocks investigated in this study. The maximum observation percentage was $53 \%$, while several blocks where plumes were observed displayed visible oil slicks in less than $7 \%$ of the SAR images.

There are two cases (MC433 and MC172) where OSOs complied with the clustering conditions to generate a SZ inside the boundaries of those two lease blocks. However there was no other available indication from geophysical data, multibeam, or direct observations to support the existence of oil migration on these areas. These cases will require further investigation into the geophysical data or new acquisitions of SAR imagery to determine if the oil migration actually exists on this two SZ, or if they are false-positive outputs of our process. 
Even if we assume these 2 cases are false-positives, we can report that $97 \%$ (50 out of the 52 SZ) contained supportive data to validate the presence of oil migration.

The aerial survey results also comport with intermittent sources. A prominent oil slick detected to the northeast of the DWH site on 5 October 2012, was not present one month later when the site was overflown in conjunction with R/V Falkor operations, nor was it seen in subsequent overflights (B. Schumaker, unpublished data). Aerial surveys also detected small releases producing oil slicks $\sim 100 \mathrm{~m}$ in length, which are below the resolution of the SAR imagery used.

An example of variability in oil discharge rates variability is shown in Figure 7. The SAR image subsets in this display are from images collected at different times using the same SAR satellite and resolution type (C-Band, RADARSAT 1-2) under optimal weather conditions for oil slick detection (winds of 3-7m/s). SAR images were collected by Radarsat-1 on 22 April 2003 at 11:54 UTC and 16 May 2003 at 11:54 UTC). In the 22 April image (Figure 7A), relatively small oil slicks can be observed emanating from SZ in MC302, MC389, and MC434, while many other SZ locations appear inactive. Note that the location of an oil slick origin is often displaced from its seafloor vent due to mid-water currents. In the 16 May image (Figure 7B), seeps have been activated in MC124 and MC388; the oil slick emanating from MC302 has increased dramatically in size and the MC434 SZ appears inactive. An image taken by the same satellite under similar conditions on 3 June 2004 shows oil slicks emanating from most or all of the SZ (Figure 7C). The final image in this series was collected on 26 August 2011 at 23:57 UTC by RADARSAT-2 (Figure 
7D). In this case, a distinct oil slick was observed emanating from the MC124 SZ, while discharges from the other $\mathrm{SZ}$ are greatly reduced in scale or absent. This intermittent tendency was observed throughout the SAR time series from the region.

\subsection{Discharge magnitudes}

To estimate and analyze oil fluxes in the Macondo prospect region, we used the area of the oil slicks as an indicator of the volume of oil discharges. Large oil slicks were frequently observed in this region during the last months of 2011. These releases mainly sourced on the lease block MC252 appeared to be related to the wrecked DeepWater Horizon. To avoid confusing oil from sources associated with the DWH, we excluded those events from the analysis.

The high intermittence on the presence/absence of slicks makes difficult to evaluate the oil flux form the seeps in the region. This evaluation has to be done on a separate basis for each SZ over time. For example, the largest slick ever observed on our dataset corresponded to the SZ located on MC302 (as shown on Figure 7B). The area of the slick was $21 \mathrm{~km}$ in length and covered $14.2 \mathrm{~km}^{2}$. However, the average size of slicks detected from MC302 was $2.9 \mathrm{~km}^{2}$. To verify the oil volume analysis, we used aerial photography surveys over slicks located on the Macondo prospect region.

To estimate the volume flux of oil released from the most persistent seep in the area (MC302), based on the slick size and oil aspect observed from aerial photography we infer a 95\% of the area being $0.1 \mu \mathrm{m}$ thick and $5 \%$ of the area being $1 \mu \mathrm{m}$ thick (Macdonald et al., 
1993). This instantaneous volume can then be multiplied by the presumed survival time ( 8 -

$24 \mathrm{~h}$ ) for natural oil slicks to derive an estimate of daily flux (MacDonald et al., 2002). This estimate of survival time is based on the observation that natural oil slicks continuously change their shape and direction of drift over time-scales $<24 \mathrm{~h}$, which was consistent with the observations in this regions of the Gulf of Mexico. On-going research on survival of natural oil slicks indicates that the survival times for natural oil slicks can be quite variable (MacDonald, 2013), so these fluxes are approximate.

\section{Discussion}

The large archive of remote sensing data, in combination with geophysical and multibeam data, made it possible to map and characterize the natural hydrocarbon seeps in the Macondo prospect region. When the locations of all oil slick origins (OSO) observed in the 219 SAR images are overlain in a single plot (Fig. 1B), it appears as if the region were covered with a high density of surface oil slicks. This is an erroneous interpretation of the data, however, because the ocean surface locations of OSOs imaged at any given time will migrate within a radius of several kilometers from their seafloor sources. Cluster analysis of OSO locations indicates that there are about 52 separate sources in total over a $~ 50 \times 50 \mathrm{~km}$ area. Estimates of discharge volumes present in floating oil slicks were verified by high resolution aerial photography. The seafloor characteristics of seeps in the Mississippi Canyon area closest to the DWH sites was verified by direct observation from the submarine Alvin.

These results demonstrate clear differences between natural seeps in the Mississippi Canyon region near the DWH site and the natural seeps known from the northwestern Gulf of 
Mexico in the Green Canyon and Garden Banks areas (sarsea.org/MC852_seeps). A major distinction was intermittent discharge from Mississippi Canyon seeps. Whereas northwestern GOM seeps were persistent over monthly, annual, and decadal observation intervals (De Beukelaer et al., 2003; Garcia-Pineda et al., 2010), the MC region seeps were persistent at most among $53 \%$ of the remote sensing observations, with most seeps having been detected in fewer than $25 \%$ of the SAR images (Fig. 2).

To further characterize the regional differences among northern GOM seeps, we estimated the volume of output to the floating oil slicks. Using the slick polygons of those images selected during ideal wind conditions, we calculated the percent of the area covered by slicks over the lease blocks on each of the 42 images. We then normalized the areas by averaging the percentages by the number of observations in each lease block. The result of this analysis is the average oil cover on each of the lease blocks. By applying the thickness values of $95 \%$ of the area being $0.1 \mu \mathrm{m}$ thick and $5 \%$ of the area being $1 \mu \mathrm{m}$ thick, we can estimate the oil volume per lease block over time (Fingas, 1998; Macdonald et al., 1993). Figure 8 shows a color scale map representing the volume estimates per lease block. Because floating oil rapidly loses mass to evaporation and dispersion (Fingas, 1998; MacDonald et al., 2002), these estimates represent a lower bound on the probable actual flux rates, which may be as much as $100 \%$ greater. However, the estimates allow us to compare the relative rates across the region. A recent study of methane gas flux has been conducted by the Center for Coastal and Ocean Mapping using the same multibeam dataset collected by Okeanos, shown as yellow stars in Figure 3A, (Weber et al., 2014). 
Applying similar methods to the natural seeps documented from Green Canyon (GarciaPineda et al., 2010), we find the difference in the number of seeps and the quantity of surface oil detected at Green Canyon versus Mississippi Canyon is almost of two orders of magnitude. We have quantified nearly 400 seep sites inside the boundaries of the 'GC' protraction area; versus 52 oil-producing SZ in the 'MC' region (MacDonald, 2011). The capability of SAR to detect oily seeps is also limited by its spatial resolution. New SAR technology capable of meter-scale resolution may resolve many seep sites that currently are undetected with present SAR imagery. The seeps that appear to discharge the largest volumes of oil are located in lease blocks MC258 and MC302 on the edge of the Mobile dome. Assuming that the survival time of floating oil is 24 hours, our estimates are that this cluster of seeps released in average $0.14 \mathrm{~m}^{3}$ of oil per day ( $0.91 \mathrm{bbl}$ per day). In the Macondo prospect region, the lease block with highest volume of discharge appears to be MC253. The value of such estimates is in comparing regional differences rather than calculating total fluxes because the controlling parameters (i.e. oil slick thickness and survival time) are not well constrained and because the method does not account for evaporation and dispersion (Ryerson et al., 2011).

Comparing the gas plume distribution to the locations of oil-producing SZ, we see 12 SZ where no gas plumes were detected in the multibeam surveys of 2011 or 2012 (Figure 2); whereas the remaining 40 SZ were closely associated with clusters of gas plumes. Two different scenarios could account for this. Possibly, the SZ where no gas plumes were detected may lack gas seeps. We reject this explanation because gas-free bubbles of oil will probably not have sufficient buoyancy to rise to the surface within the consistent radius of an SZ (MacDonald et 
al., 2002). A more likely cause would be that the seeps in question are intermittent and were inactive at the times when multibeam surveys were conducted.

The multibeam surveys do demonstrate widespread gas seepage in the Mississippi Canyon region (Figs. 2 and 3). It is challenging to compare these results with other regions of the Gulf of Mexico or other marine basins because multibeam instruments appear to be very sensitive to bubble backscatter, but may not distinguish small sources from larger sources. Survey results from R/V Okeanus and R/V Falkor were in no way calibrated to scale of output from the individual gas seeps that produced the backscatter targets. One of the most comprehensive investigations of gas flux and gas plumes in the water column was conducted offshore Pakistan (Römer et al., 2012). These investigators, examining seeps in 2000 m water depths using acoustic backscatter and direct measurement of bubble release, found flux rates of from 0.24 to $10.83 \mathrm{~mol} \mathrm{CH}_{4} \mathrm{~min}^{-1}$. Although we document several hundred gas plumes in this region, we do not think it advisable to extrapolate from the present results to an estimate of total gas flux. The Römer et al. (2012) results indicate a wide range in flux estimates from similar acoustic responses (Weber et al., 2014).

The geologic processes that form seep zones are similar between the two regions. Upwelling salt domes have fractured the sub-surface deposits leading to the formation of fault induced depressions. Hydrocarbon migration occurs along bedding planes to the fault systems underlying the depressions. Oil and gas migration often occurs vertically in the shallow subsurface to the seafloor creating the topographic features and seafloor amplitude anomalies that characterize the seeps on high resolution 3D seismic data. The density difference of 
lithified seep sediments to the surrounding soft sediments often exhibit well-known acoustic anomalies in the geophysical record such as seafloor reflection amplitude anomalies, zones of chaotic and attenuated reflectors as well as bright spots that may be associated with gas charged sediments, active venting and hard ground formation. Additional research will be needed to understand the geologic processes that produce such different outcomes in terms of the persistence, number, and output of natural seeps. Further exploration may reveal more fully developed seeps and seep communities than were seen in MC253 (Fig. 4). However the conclusion of this work is that natural seepage in the Mississippi Canyon region is markedly more intermittent and less productive of floating oil slicks than in the central and northwestern Gulf of Mexico.

\section{Acknowledgements}

We acknowledge salary support from the GOMRI consortia ECOGIG and Deep-C for O.G.P, I.R.M., M.S, and S.D.A. The Schmidt Ocean Institute's ship R/V FALKOR was provided at no cost in an ongoing program that facilitates access to the global ocean for researchers aligned with the Institute's vision and mission. Fieldwork on submarine ALVIN was supported by NSF project EF-0801741: MO: Collaborative Research: A Microbial Observatory Examining Microbial Abundance, Diversity, Associations and Activity At Seafloor Brine Seeps. Support from the BOEM WAMOST project (Contract M12PC00003) is also acknowledged. This is ECOGIG contribution number 301. 


\section{References}

Aeppli, C., Reddy, C.M., Nelson, R.K., Kellermann, M.Y., Valentine, D.L., 2013. Recurrent Oil Sheens at the Deepwater Horizon Disaster Site Fingerprinted with Synthetic Hydrocarbon Drilling Fluids. Environmental Science \& Technology 47, 8211-8219.

Cook, D., D'Onfro, P., 1991. Jolliet Field thrust fault structure and stratigraphy Green Canyon Block 184, offshoure Louisiana. Transactions-Gulf Coast Association of Geological Societies XLI, 100-121.

De Beukelaer, S.M., MacDonald, I.R., Guinnasso, N.L., Murray, J.A., 2003. Distinct side-scan sonar, RADARSAT SAR, and acoustic profiler signatures of gas and oil seeps on the Gulf of Mexico slope. Geo-Mar Lett 23, 177-186.

Fingas, M.F., 1998. Studies on the evaporation of crude oil and petroleum products II. Boundary layer regulation. Journal of Hazardous Materials 57, 41-58.

Frye, M., 2008. Preliminary Evaluation of In-Place Gas Hydrate Resources: Gulf of Mexico Outer Continental Shelf. U.S. Dept. Interior, Minerals Management Service, Resource Evaluation Division OCS Report MMS 2008-004, 192 pages, appendices.

Garcia-Pineda, O., MacDonald, I., Zimmer, B., Shedd, B., Roberts, H., 2010. Remote-sensing evaluation of geophysical anomaly sites in the outer continental slope, northern Gulf of Mexico. Deep-Sea Research Part II-Topical Studies in Oceanography 57, 1859-1869.

Garcia-Pineda, O.G., MacDonald, I.R., Shedd, W., 2014. Analysis of oil volume fluxes of hydrocarbon seep formations on the Green Canyon and Mississippi Canyon: a study using 3D-seismic attributes in combination with satellite and acoustic data. SPE Reservoir Evaluation \& Engineering-Formation 16, DOI 10.2118/169816-PA.

Garcia-Pineda Oscar, Z.B., Howard Matt, Pichel William, Li Xiaofeng, MacDonald lan R. , 2009. Using SAR images to delineate ocean oil slicks with a texture-classifying neural network algorithm (TCNNA). Canadian Journal of Remote Sensing 35, 411-421.

Judd, A., Hovland, M., 2007. Submarine Fluid Flow, the Impact on Geology, Biology, and the Marine Environment. Cambridge University Press.

Kvenvolden, K.A., Cooper, C.K., 2003. Natural seepage of crude oil into the marine environment. GeoMar Lett 23, 140-146. 
Leifer, I., MacDonald, I., 2003. Dynamics of the gas flux from shallow gas hydrate deposits: interaction between oily hydrate bubbles and the oceanic environment. Earth Planet Sc Lett 210, 411-424.

MacDonald, I.R., 2011. Remote Sensing and Sea-Truth Measurements of Methane Flux to the Atmosphere (HYFLUX project). National Energy Technology Laboratory, Dept. of Energy DOE Award No.: DE-NT0005638, Final report, 85 pages, 85 appendices.

MacDonald, I.R., 2013. Surface oil drift rates estimated from natural seeps, 2013 Gulf of Mexico Oil Spill \& Ecosystem Science Conference. Gulf of Mexico Research Initiative, New Orleans, LA.

MacDonald, I.R., Buthman, D., Sager, W.W., Peccini, M.B., Guinasso Jr., N.L., 2000. Pulsed oil discharge from a mud volcano. Geology 28, 907-910.

Macdonald, I.R., Guinasso, N.L., Ackleson, S.G., Amos, J.F., Duckworth, R., Sassen, R., Brooks, J.M., 1993. NATURAL OIL-SLICKS IN THE GULF-OF-MEXICO VISIBLE FROM SPACE. J. Geophys. Res.-Oceans 98, 16351-16364.

MacDonald, I.R., Leifer, I., Sassen, R., Stine, P., Mitchell, R., Guinasso, N., 2002. Transfer of hydrocarbons from natural seeps to the water column and atmosphere. Geofluids 2, 95-107.

MacDonald, I.R., Peccini, M.B., 2009. Distinct activity phases during the recent geologic history of a Gulf of Mexico mud volcano. Mar Petrol Geol 26, 1824-1830.

MacDonald, I.R., Sager, W.W., Peccini, M.B., 2003. Association of Gas Hydrate and Chemosynthetic Fauna in Mounded Bathymetry at Mid-Slope Hydrocarbon Seeps: Northern Gulf of Mexico. Mar Geol 198, 133-158.

Nikolovska, A., Sahling, H., Bohrmann, G., 2008. Hydroacoustic methodology for detection, localization, and quantification of gas bubbles rising from the seafloor at gas seeps from the eastern Black Sea. Geochem Geophy Geosy 9, -.

NOAA Hazmat, 2012. OPEN WATER OIL IDENTIFICATION JOB AID for aerial observation. Office of Response and Restoration Version 2.

Reilly, J.F., MacDonald, I.R., Biegert, E.K., Brooks, J.M., 1996. Geologic controls on the distribution of chemosynthetic communities in the Gulf of Mexico, in: Schumacher, D., Abrams, M.A. (Eds.), Hydrocarbon migration and its near-surface expression. Amer. Assoc. Petrol. Geol., Tulsa, OK, pp. 38-61. 
Roberts, H., Wiseman Jr., W., Hooper, J., Humphrey, G., 1999. Surficial gas hydrates of the Louisiana continental slope--initial results of direct observations and in situ data collection, Offshore Technology Conference. Offshore Technology Conference, Houston, TX, pp. 259-272.

Roberts, H.H., Carney, R.S., 1997. Evidence of episodic fluid, gas, and sediment venting on the northern Gulf of Mexico continental slope. Economic Geology and the Bulletin of the Society of Economic Geologists 92, 863-879.

Roberts, H.H., Shedd, W., Hunt, J., Jr., 2010. Dive site geology: DSV ALVIN (2006) and ROV JASON II (2007) dives to the middle-lower continental slope, northern Gulf of Mexico. Deep-Sea Research Part li-Topical Studies in Oceanography 57, 1837-1858.

Römer, M., Sahling, H., Pape, T., Bohrmann, G., Spieß, V., 2012. Quantification of gas bubble emissions from submarine hydrocarbon seeps at the Makran continental margin (offshore Pakistan). Journal of Geophysical Research: Oceans 117, C10015.

Ryerson, T.B., Aikin, K.C., Angevine, W.M., Atlas, E.L., Blake, D.R., Brock, C.A., Fehsenfeld, F.C., Gao, R.S., de Gouw, J.A., Fahey, D.W., Holloway, J.S., Lack, D.A., Lueb, R.A., Meinardi, S., Middlebrook, A.M., Murphy, D.M., Neuman, J.A., Nowak, J.B., Parrish, D.D., Peischl, J., Perring, A.E., Pollack, I.B., Ravishankara, A.R., Roberts, J.M., Schwarz, J.P., Spackman, J.R., Stark, H., Warneke, C., Watts, L.A., 2011. Atmospheric emissions from the Deepwater Horizon spill constrain air-water partitioning, hydrocarbon fate, and leak rate. Geophysical Research Letters 38.

Sassen, R., Sweet, S.T., DeFreitas, D.A., Morelos, J.A., Milkov, A.V., 2001. Gas hydrate and crude oil from the Mississippi Fan Foldbelt, downdip Gulf of Mexico salt basin: significance to petroleum system. Mar Geol 32, 999-1008.

Weber, T.C., Mayer, L., Jerram, K., Beaudoin, J., Rzhanov, Y., Lovalvo, D., 2014. Acoustic estimates of methane gas flux from the seabed in a $6000 \mathrm{~km} 2$ region in the Northern Gulf of Mexico. Geochemistry, Geophysics, Geosystems 15, 1911-1925.

Whelan, J., Eglinton, L., Cathles, L., Losh, S., Roberts, H., 2005. Surface and subsurface manifestations of gas movement through a N-S transect of the Gulf of Mexico. Mar Petrol Geol 22, 479-497. 


\section{Figure Captions}

Figure 1. Study area maps: A) Study area is situated southeast of Mississippi River Delta (inset) within the Mississippi Canyon leasing area for offshore energy exploration and production. Grid shows lease block boundaries and designations. Deepwater Horizon (DWH) wreck site is located in MC252 block. B) Location of all OSO (oil slick origin) points detected in 219 SAR images. Background bathymetry shows locations of salt domes in the vicinity of the DWH wreck site.

Figure 2. Location of SZ in the Macondo area. Black circles represents the location of the oily SZ and white boxes represents locations of gassy SZ.

Figure 3. A) Gas Plumes detected with swath-mapping multibeam surveys during the Okeanos and Falkor expeditions. B) Multibeam results from R/V Falkor showing gas plumes originating from the flanks of Biloxi and Gloria domes, and from the Deepwater Horizon wreck and debris field, which appeared as distinct reflectors on the seafloor. Lateral distances show spacing of seeps; vertical distances are height of bubble plumes in water column.

Figure 4. A) Geophysical anomalies identified on the seismic data appear mainly at the edge of prominent salt domes. Red line that crosses domes and DWH site shows the map path of the seismic profile. B) Seismic profile through map points. Dotted line at point $C$ shows trace of Macondo Well. Apparent bathymetric high at $C$ is artifact of profile track on slope.

Figure 5. Active seep on Gloria Dome near $28^{\circ} 43.32^{\prime} \mathrm{N}, 88^{\circ} 19.60^{\prime} \mathrm{W}$ at a depth of $1467 \mathrm{~m}$. Carbonate rubble, bivalve shells, and sparse tubeworm tubes were coated with microbial communities and a white precipitate. Detail shows bubbles of oil slowly escaping from the sediment interface. 
Figure 6. Aerial photographs of smaller and larger oil slicks: A) Small drops surfacing over the DWH site near R/V Falkor (ship is $83 \mathrm{~m}$ total length). B) Map of vicinity shows georectified mosaic of digital photographs taken from a small plane using a vertically mounted camera and flying at an altitude of about $150 \mathrm{~m}$. Rainbow sheen at northeast end indicates the oil slick origin (arrow). Details show wreckage of the DWH drilling rig and riser as well as locations of relief wells. The small oil slicks observed in 6A originated from this debris, whereas the larger oil slick in 6B had a different origin.

Figure 7. Examples of intermittent oil slick formation in Mississippi Canyon study area visualized by satellite SAR under similar wind conditions $\left(3-7 \mathrm{~ms}^{-1}\right)$. Region shown contains the most active seeps in the Dauphine dome area (MC344, MC345, MC388, MC389). All images were collected when wind speeds were in the optimal range for visualizing oil slicks (3-7 $\mathrm{ms}^{-1}$ ). Image collection times are as follows: A) Radarsat 1 at 11:58UTC 22 April 2003; B) Radarsat 1 at 11:54UTC 16 May 2003; C) Radarsat 1 at 11:53UTC 3 June 3002; D) Radarsat 2 at 23:57UTC 26 August 2011.

Figure 8. Oil Volume estimate of liquid oil per day for the lease blocks in the Mississippi Canyon study area. Estimated from average size of floating slicks imaged in 219 satellite SAR. 
Table 1. Summary of SAR dataset collected over the Mississippi Canyon study area (Fig. 1) by available satellite sensors during three periods.

\begin{tabular}{|c|c|c|c|c|}
\hline SATELLITE & $\begin{array}{l}\text { PRE-DWH } \\
(1978-2010)\end{array}$ & $\begin{array}{l}\text { DURING DWH } \\
\text { (APR-AUG 2010) }\end{array}$ & $\begin{array}{c}\text { POST-DWH } \\
(2012)\end{array}$ & TOTAL \\
\hline ENVISAT & & 69 & 58 & \\
\hline RADARSAT1 & 225 & 22 & & \\
\hline RADARSAT2 & & 43 & 1 & \\
\hline COSMOSKY & & 77 & 68 & \\
\hline TERRASAR & & 17 & 1 & \\
\hline ALOS & & 13 & & \\
\hline SPOT & & 19 & & \\
\hline ERS & & 9 & & \\
\hline SEASAT & 27 & & & \\
\hline JERS-1 & 91 & & & \\
\hline TOTAL & 343 & 269 & 128 & 740 \\
\hline
\end{tabular}


Garcia et al. Hydrocarbon Seepage in Mississippi Canyon

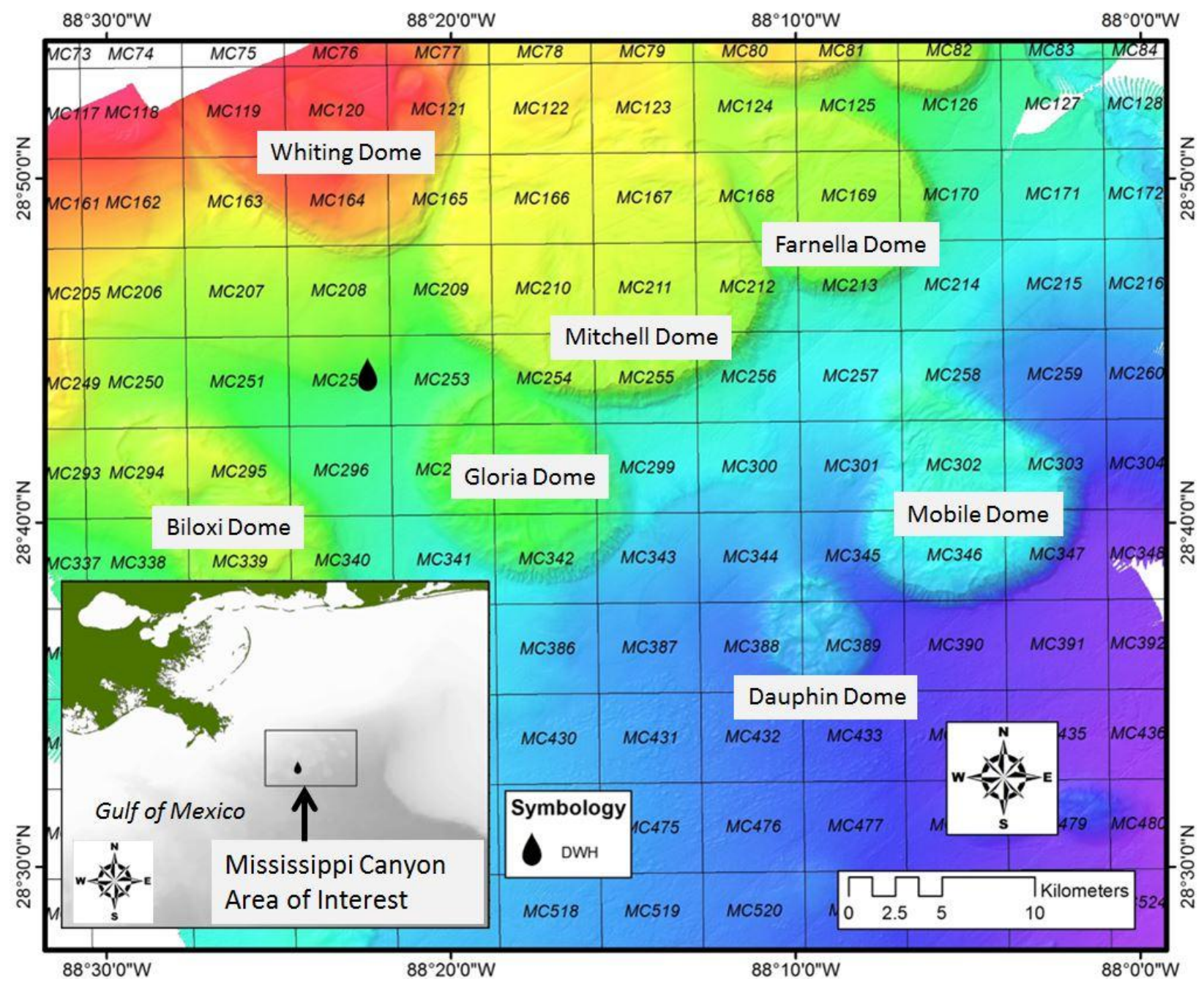


Garcia et al. Hydrocarbon Seepage in Mississippi Canyon

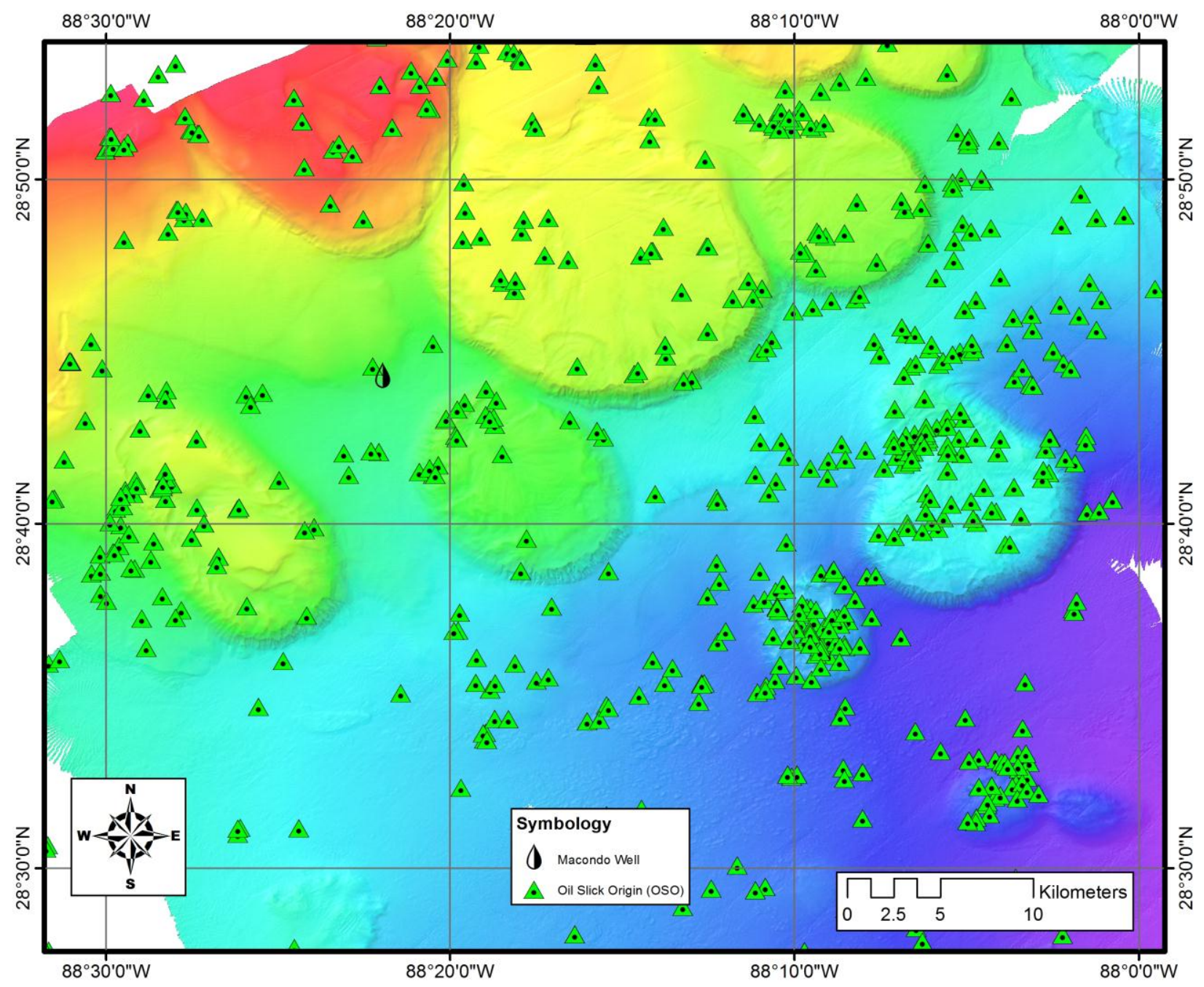




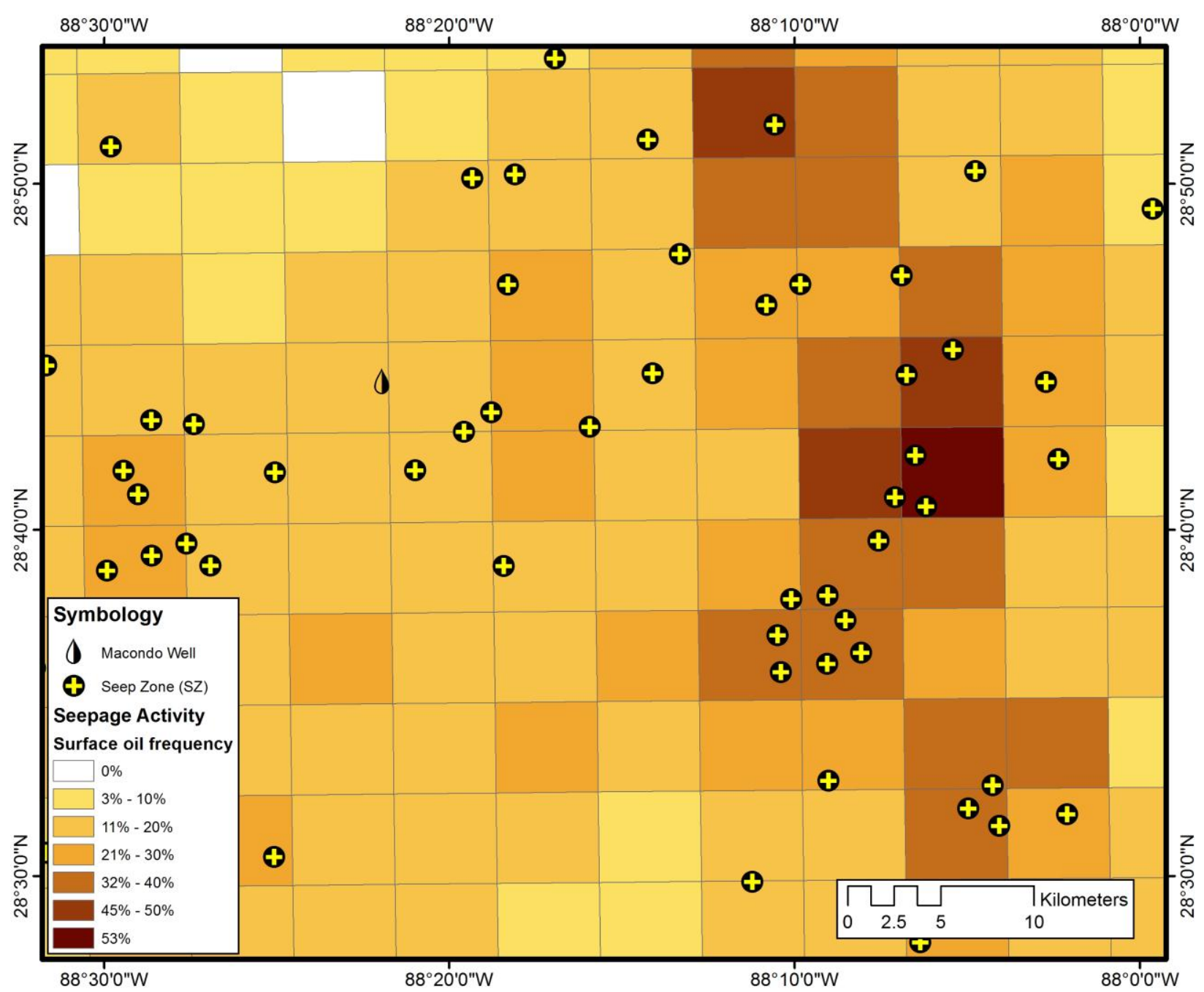




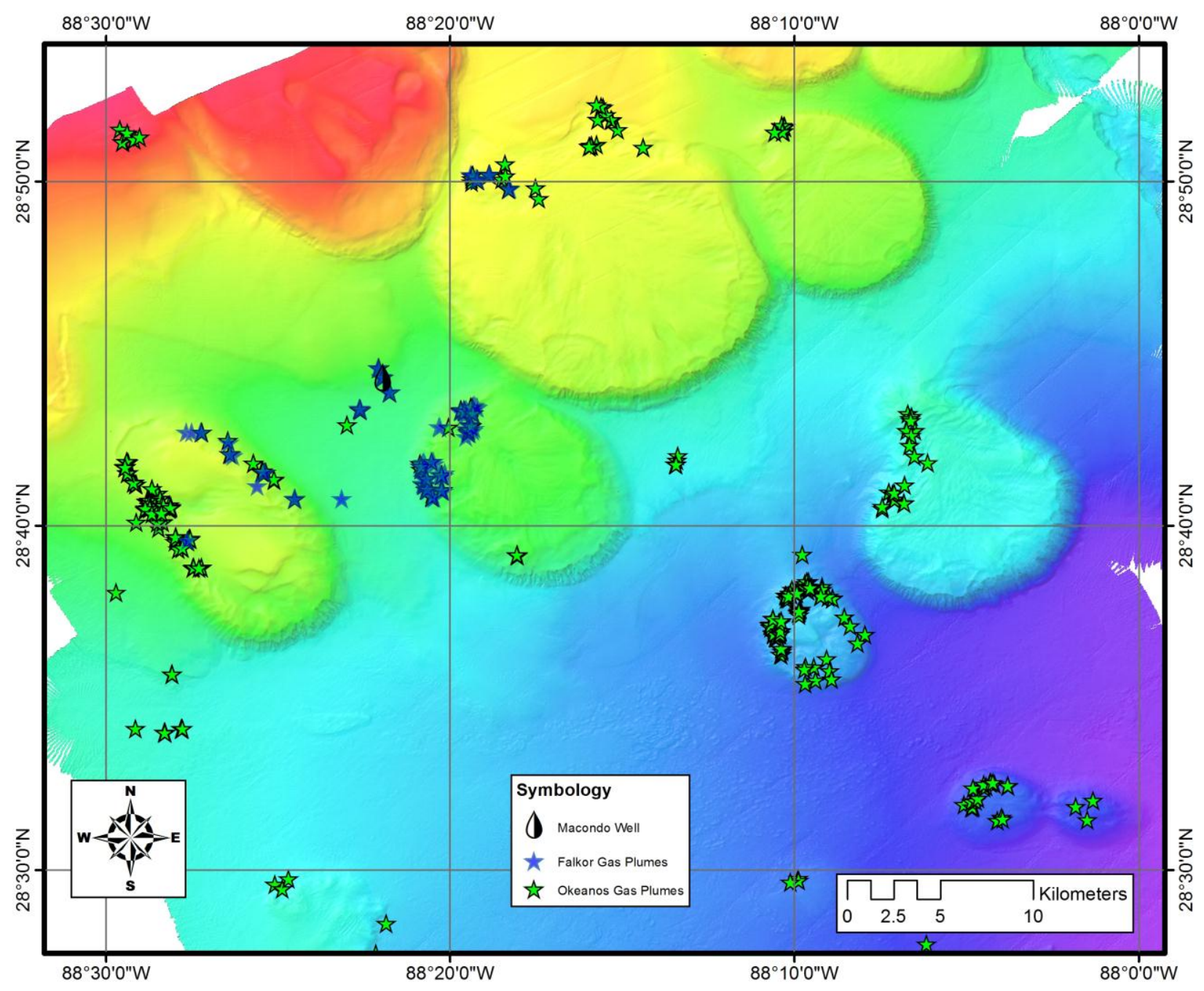


Garcia et al. Hydrocarbon Seepage in Mississippi Canyon

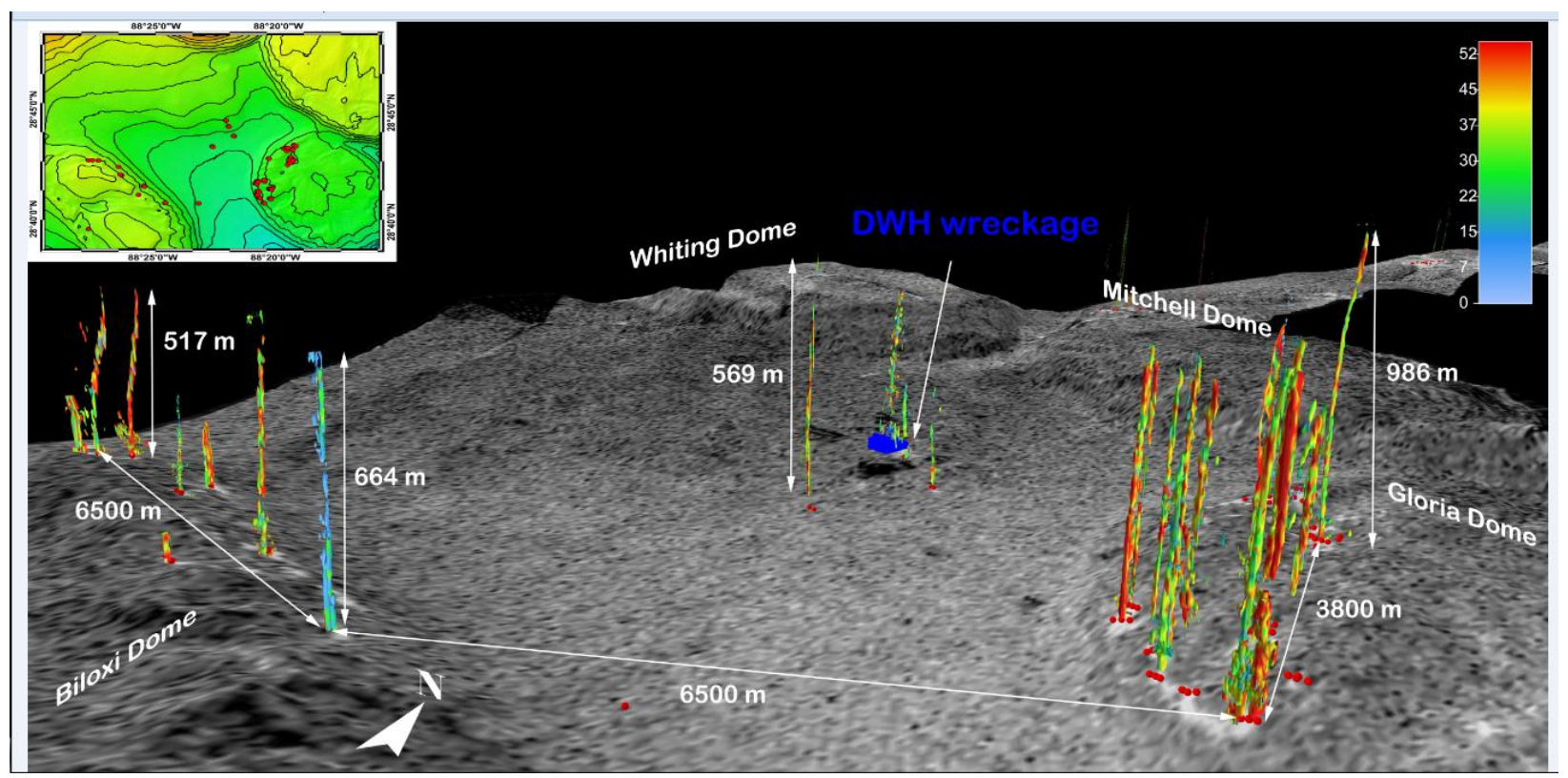


Garcia et al. Hydrocarbon Seepage in Mississippi Canyon

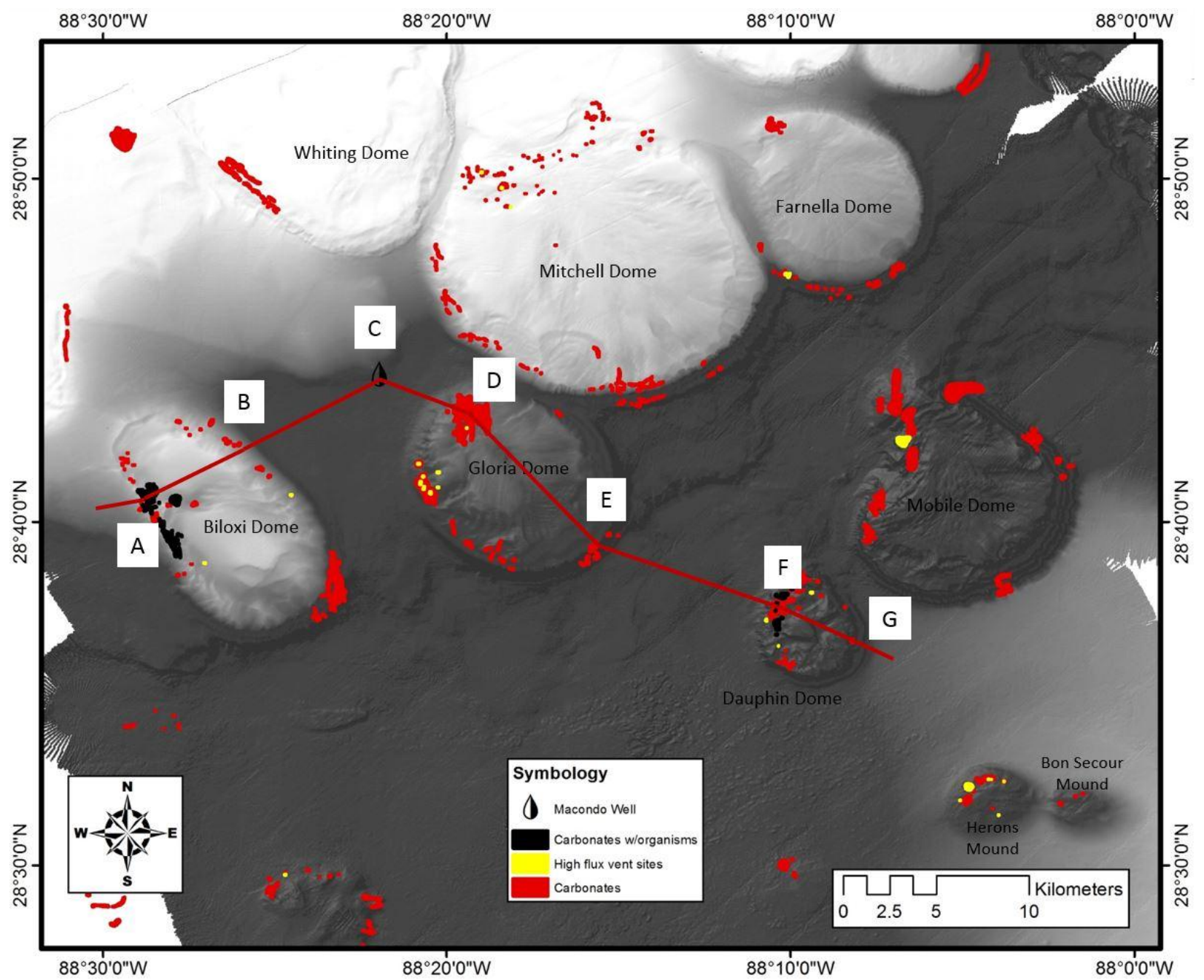


Garcia et al. Hydrocarbon Seepage in Mississippi Canyon

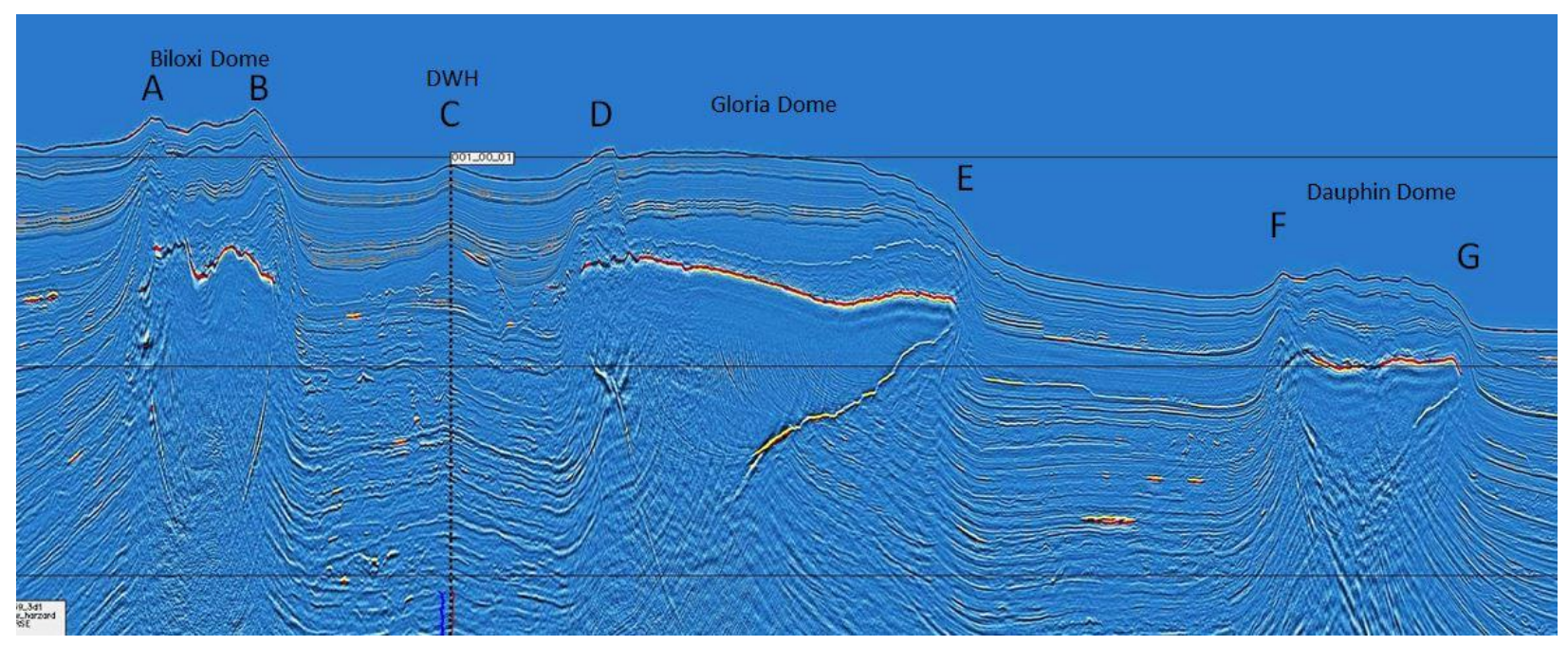


Garcia et al. Hydrocarbon Seepage in Mississippi Canyon

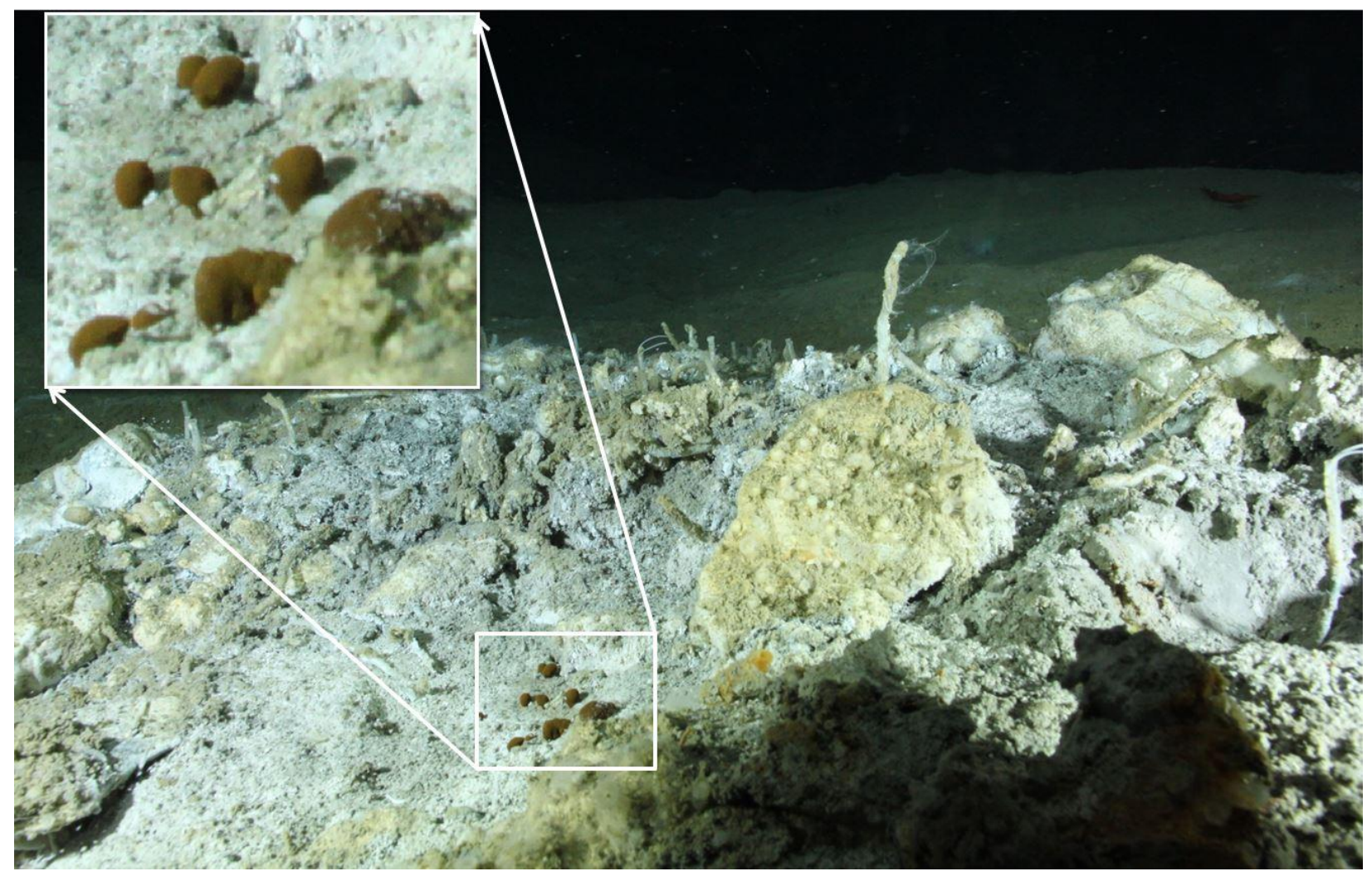


Garcia et al. Hydrocarbon Seepage in Mississippi Canyon

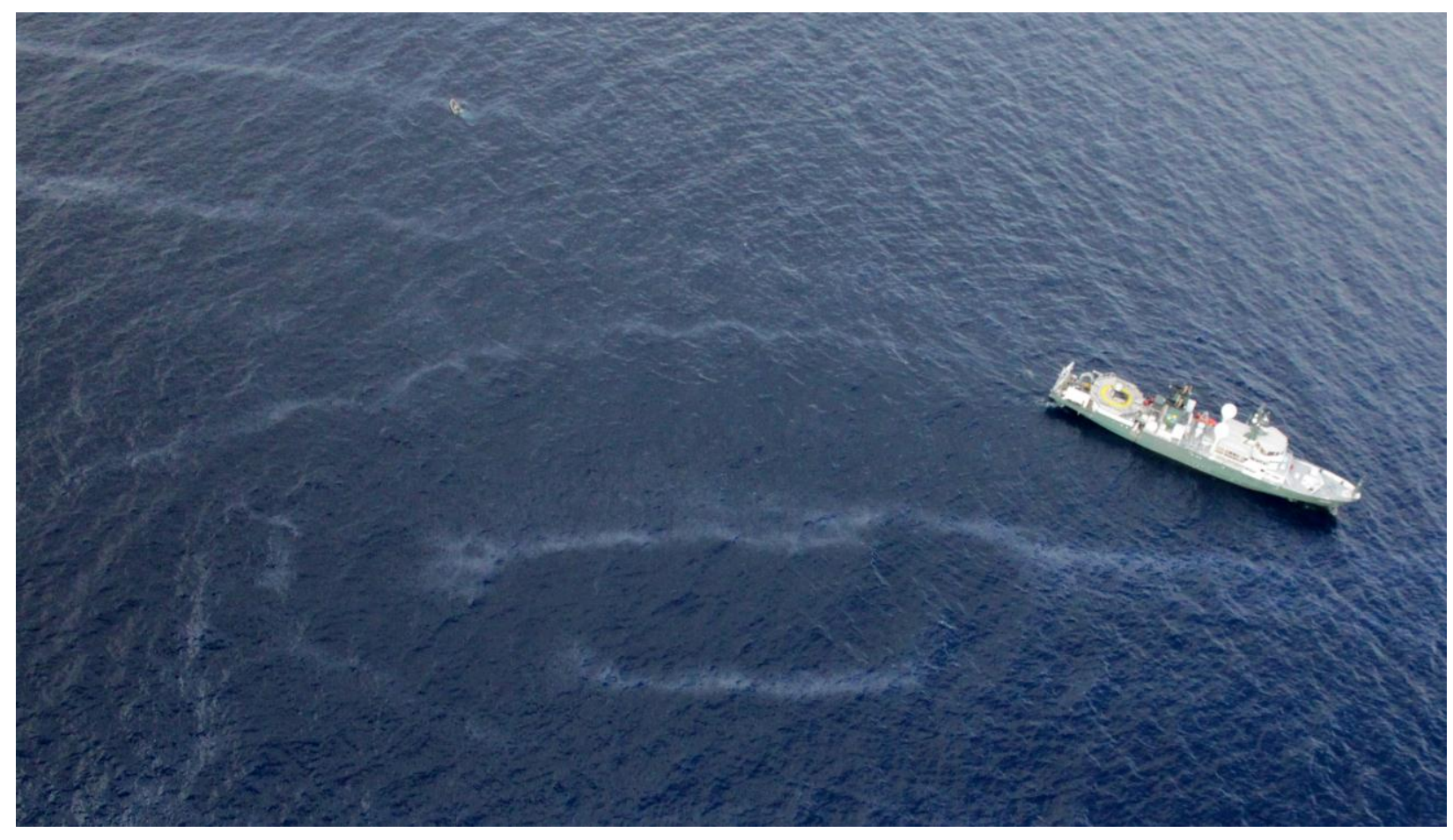




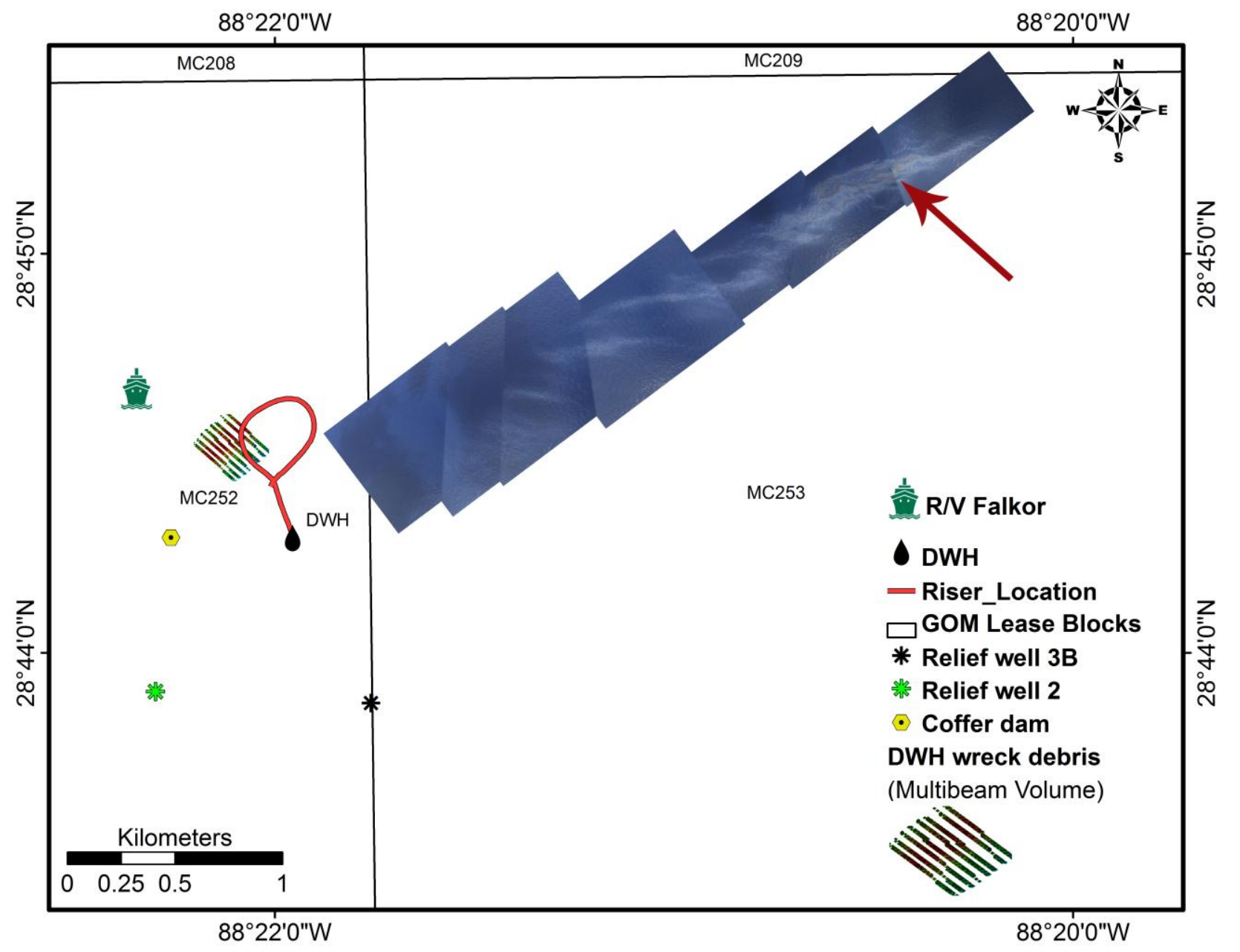


Garcia et al. Hydrocarbon Seepage in Mississippi Canyon

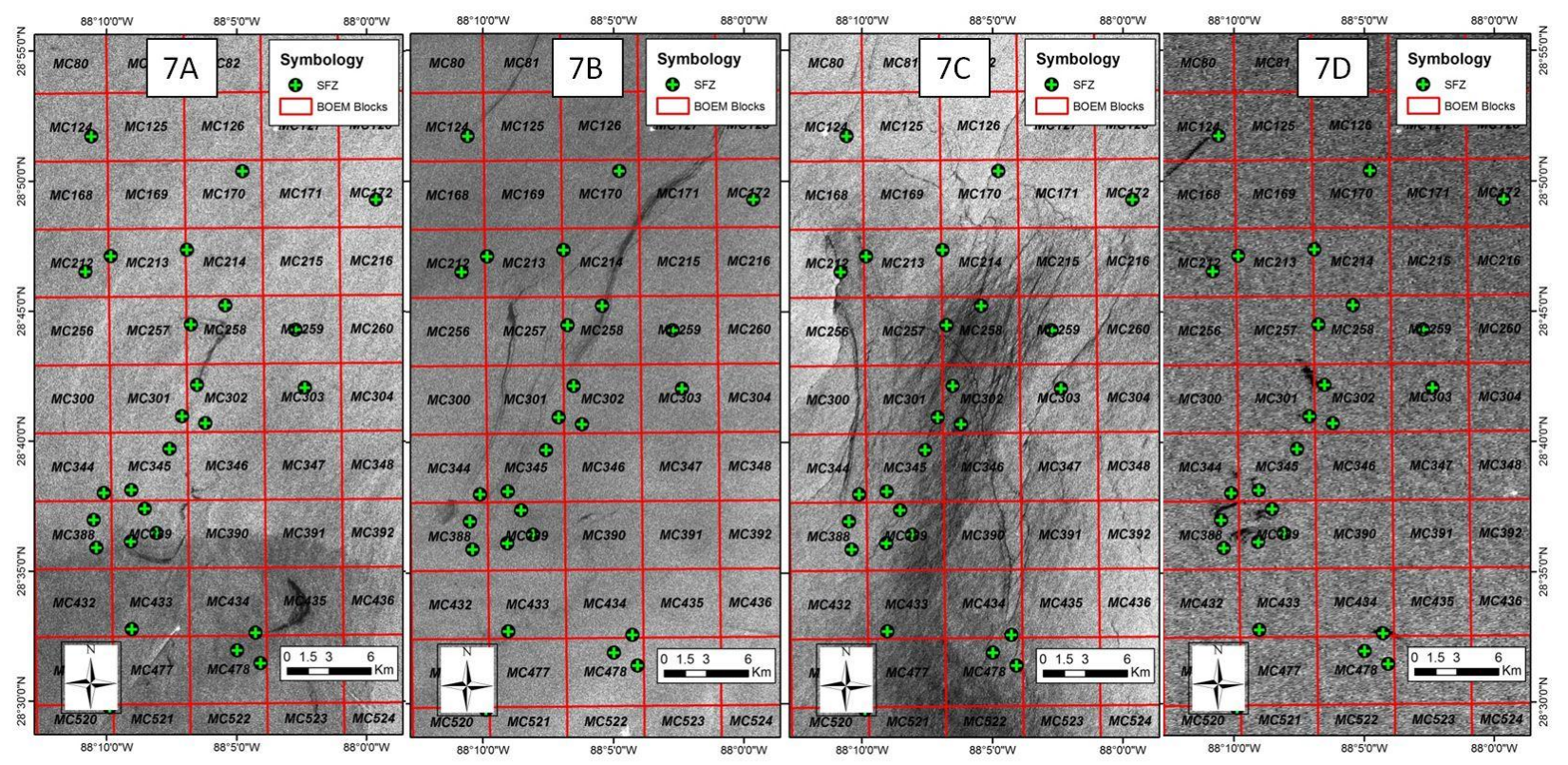


Garcia et al. Hydrocarbon Seepage in Mississippi Canyon

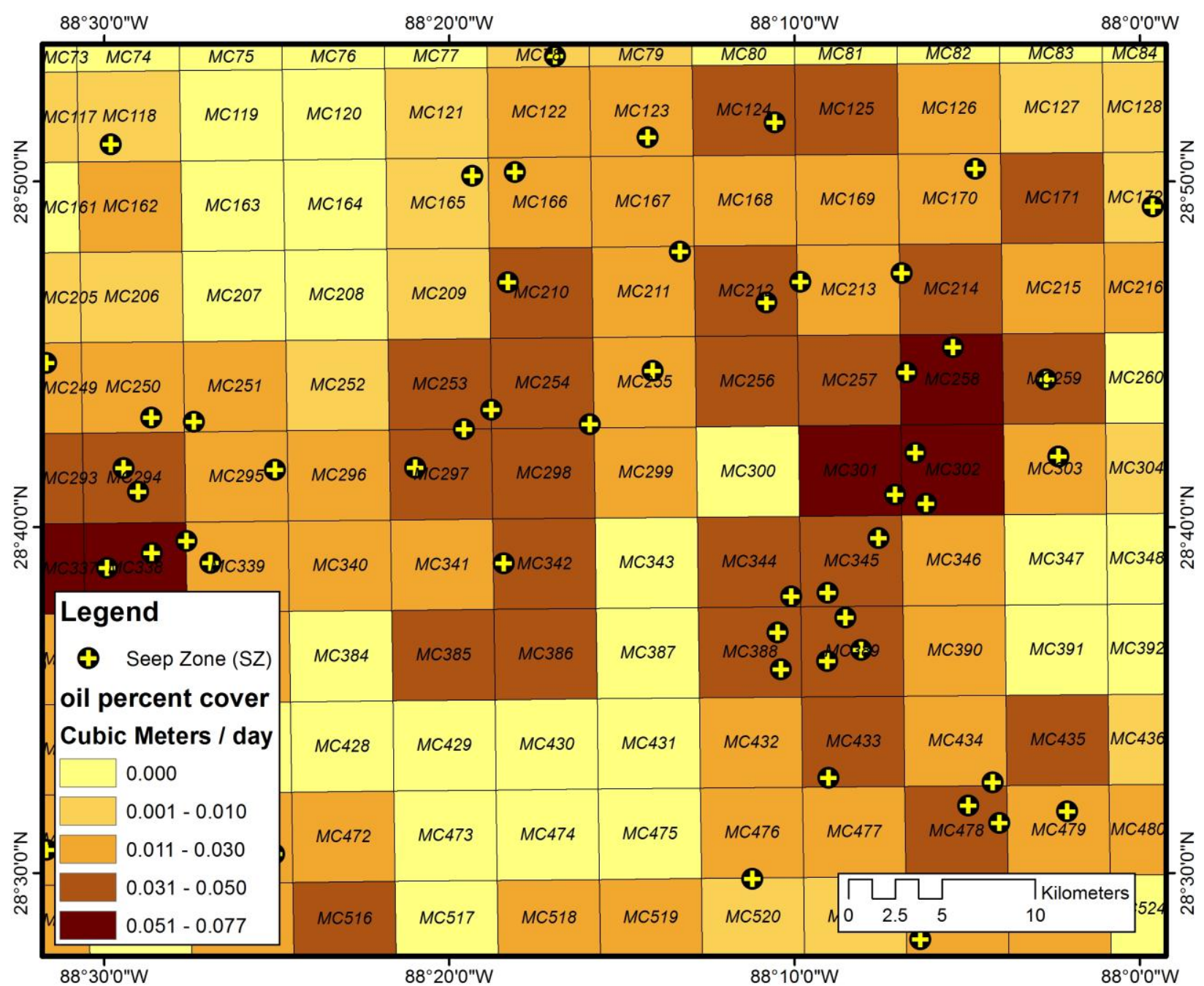

